\title{
Optimization Analysis of the Position of Thermometers Buried in Concrete Pouring Block Embedded with Cooling Pipes
}

\author{
Yaoying Huang $\left(\mathbb{D},{ }^{1}\right.$ Tong Xie $\mathbb{I D}^{1},{ }^{1}$ Chunguang $\mathrm{Li}^{2}$, and Xiaohui Yin $\mathbb{D}^{1}$ \\ ${ }^{1}$ College of Hydraulic and Environmental Engineering, China Three Gorges University, Yichang, Hubei 443002, China \\ ${ }^{2}$ State Key Laboratory of Geomechanics and Geotechnical Engineering, Institute of Rock and Soil Mechanics, \\ Chinese Academy of Sciences, Wuhan, Hubei 430071, China
}

Correspondence should be addressed to Yaoying Huang; huangyaoying@sohu.com

Received 19 March 2019; Revised 11 May 2019; Accepted 11 June 2019; Published 1 July 2019

Academic Editor: Łukasz Jankowski

Copyright (C) 2019 Yaoying Huang et al. This is an open access article distributed under the Creative Commons Attribution License, which permits unrestricted use, distribution, and reproduction in any medium, provided the original work is properly cited.

\begin{abstract}
The measured temperature of a concrete pouring block depends strongly on the position of the buried thermometer. Only when the temperature measured by the thermometer accurately reflects the actual temperature of the concrete pouring block do reasonable temperature-control measures become possible. However, little research has been done on how to determine the proper position of thermometers buried in a concrete pouring block embedded with cooling pipes. To address this situation, we develop herein a method to determine the position of thermometers buried in a concrete pouring block. First, we assume that the design temperature-control process line characterizes the average-temperature history of the concrete pouring block. Under this assumption, we calculate the average-temperature history of the concrete pouring block by using the water-pipe-cooling FEM, following which the temperature history of an arbitrary point in the concrete pouring block is obtained by interpolating the shape function. Based on the average-temperature history of the concrete pouring block and the temperature history of the arbitrary point, we build a mathematical model to optimize the buried position of the thermometer and use the optimization algorithm to determine this position. By using this method, we establish finite-element models of concrete prisms with four typical water-pipe spacing cases for concrete-dam engineering and obtain the geometric position of the thermometers by using the optimization algorithm. By burying thermometers at these positions, the measured temperature should better characterize the average-temperature history of the concrete pouring block, which can provide useful information for regulating the temperature of concrete pouring blocks.
\end{abstract}

\section{Introduction}

Numerous engineering practices have shown that massive concrete structures often have large tensile stresses due to variations in temperature during construction, which often cause cracks in the structure that may destroy the integrity of the structure, reduce the durability of the structure, and cause greater damage $[1,2]$. To prevent cracking in such concrete structures, engineering practice often calls for anticracking measures, such as selecting reasonable structural forms, optimizing the concrete mix ratio, precooling the aggregate, cooling with embedded water pipes, and preserving surfaceheat. During the construction period, water-pipe cooling is an important temperature-control measure for mass concrete. In this technique the concrete temperature is reduced by embedding water pipes in mass concrete and flowing lowtemperature water through the pipes.

In the early 1930s, the US Bureau of Reclamation studied artificial cooling methods for concrete dams when designing the Hoover Gravity Arch Dam (the world's tallest concrete dam). In 1931, the US Bureau of Reclamation conducted a water-pipe-cooling field test at the Owyhee Dam, with the results showing that water-pipe cooling is very effective. Two years later, when construction began on Hoover Dam, water-pipe cooling was fully exploited with good results. Following this experience, the water-pipe cooling method has been widely used worldwide for temperature control of mass concrete during construction [3-6]. Because the temperature and stress fields of concrete are so complicated during the water-pipe-cooling process, the US Bureau of Reclamation 
first provided a method to calculate the temperature field of a single steel cooling pipe without a heat source. Since then, numerical simulations of water-pipe cooling have always been an important research topic [7-14].

Since then, water-pipe cooling has been found to be a double-edged sword during actual engineering applications $[15,16]$. Although water-pipe cooling effectively reduces the maximum temperature during the construction period and rapidly reduces the dam temperature to the target temperature, it can cause large tensile stress near the water pipe when the cooling water starts to flow and, if the cooling rate is too high, it may cause cracking. To solve this problem, Zhu [17] proposed the principle of using water cooling to achieve "small temperature differences, early cooling, and slow cooling." Today, this principle of water cooling is widely used for constructing high dams. For example, the designer of the Xiluodu high arch dam project divided the water-pipe cooling into three phases and nine stages based on numerous numerical temperature-control calculations and on previous experience with arch-dam temperature control, crackprevention characteristics, and engineering analogies [18]. A staged cooling process line, which is also called the design temperature-control process line, was established to stipulate the target temperature, the rate of change of temperature for each stage, etc. Based on the design temperature-control process line and the temperature measured by the thermometers buried in the concrete pouring block, the constructors could regulate and control the water cooling. When the measured temperature reached the joint closure temperature, the constructors could stop the water cooling and begin to implement the joint grouting. The engineering practice used for the Xiluodu high arch dam project has shown that water cooling is a good way to control temperature and prevents cracks.

The analysis of the design temperature-control process line shows that this line actually represents the averagetemperature history of the concrete pouring block. Thus, the thermometers must be buried in the concrete pouring block to properly monitor its temperature. However, because of the large size of the concrete pouring block and the limitations imposed by construction-site conditions and costs, only a small number of thermometers could be buried in each concrete pouring block. Previous experience with the temperature-control process has shown that, during the cooling period, the temperature field of the concrete pouring block is so complicated that the measured temperature is too low (high) when the thermometers are buried too close to (too far from) the water pipe. Therefore, we must determine the appropriate geometric position at which to bury the thermometers in the concrete pouring block so that the measured temperature properly reflects the averagetemperature history of the concrete pouring block, which is crucial to obtain good monitoring results $[19,20]$.

The optimal arrangement of the monitoring instruments should deliver the most reliable information possible with the minimum number of sensors. At present, significant literature exists on the dynamic monitoring system of bridges and frame structures and the optimal arrangement of highdam sensors, but few reports are available on the optimal arrangement of temperature sensors for concrete pouring blocks [21-23]. Therefore, this paper combines the optimization algorithm and the water-pipe-cooling FEM to determine the geometric position of the buried thermometer in the concrete pouring block. We discuss the distribution of the positions of the buried thermometers in the concrete pouring block in the hope that this method of calculation may be used as a reference for monitoring temperature.

\section{Basic Principle of Water-Pipe-Cooling Simulation}

In the construction of mass concrete, water-pipe cooling is an important temperature-control measure. However, simulating the temperature field generated by water-pipe cooling, in particular the temperature gradient near the water pipe, has always been difficult. In general, two types of calculation models are currently available for analyzing the cooling of a concrete dam embedded with cooling pipes: the waterpipe-cooling FEM and the water-pipe-cooling equivalent equation of heat conduction [10]. The water-pipe-cooling FEM requires a dense finite-element mesh near the water pipe to properly describe the temperature gradient near the water pipe and then uses an iterative method to calculate the change in water temperature along the water pipe to obtain the temperature field. The water-pipe-cooling equivalent equation of heat conduction, however, considers the water pipe as a negative heat source and considers the average effect of water-pipe cooling. Thus, this method requires no dense finite element mesh near the water pipe, so the temperature field may be obtained by using a normal mesh.

In engineering practice, obtaining the temperature field by using a densely divided mesh increases the workload and difficulty of the calculation. Therefore, simulating the waterpipe-cooling effect by using normal meshing is more popular in engineering practice. Although complicated pretreatment may be avoided by using the water-pipe-cooling equivalent equation of heat conduction, the temperature gradient near the water pipe is not properly considered. To obtain an accurate temperature distribution of a concrete pouring block embedded with cooling pipe, we thus use in this work the water-pipe-cooling FEM to calculate the temperature field because it is more in line with the actual situation $[8,24,25]$. The following is a brief introduction to the basic principles of the water-pipe-cooling FEM $[1,8,12]$.

Consider a section of the cooling-water pipe, as shown in Figure 1. According to Fourier's law of heat conduction, the heat flux through the concrete on the outer wall of the water pipe is $q=-\lambda \partial T / \partial n$. In Figure 2, when calculating the heat exchange between the concrete and the water between sections $\mathrm{W}_{1}$ and $\mathrm{W}_{2}$ and during the time interval $d t$, we neglect the thermal energy contained in the wall of the water pipe itself because this wall is quite thin.

The thermal energy transferred from concrete to water through the inner surface $\Gamma^{0}$ of the water pipe section is

$$
\mathrm{d} Q_{c}=\iint_{\Gamma^{0}} q_{i} \mathrm{~d} s \cdot \mathrm{d} t=-\lambda \iint_{\Gamma^{0}} \frac{\partial T}{\partial n} \mathrm{~d} s \cdot \mathrm{d} t
$$




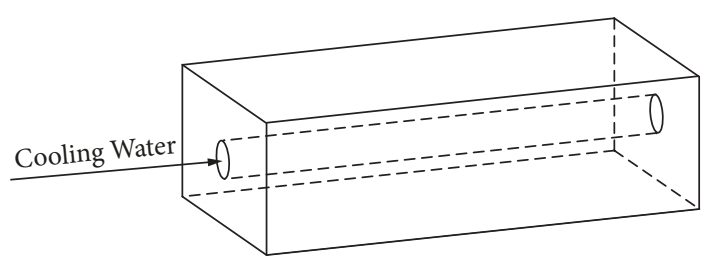

FIGURE 1: Schematic diagram of cooling pipe in concrete.

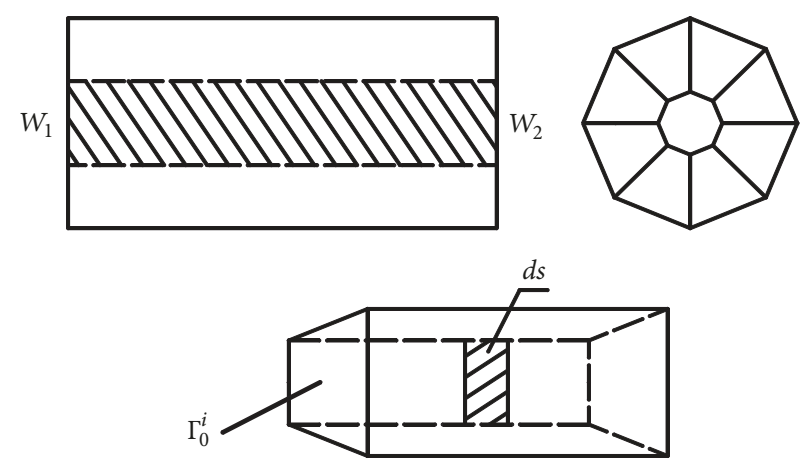

FIGURE 2: Exchange faces of heat convection in pipe cooling.

The thermal energy of the water flowing through the inlet section $\mathrm{W}_{1}$ is

$$
\mathrm{dQ}_{\mathrm{W}_{1}}=c_{\mathrm{w}} \rho_{\mathrm{w}} T_{\mathrm{W}_{1}} q_{\mathrm{w}} \mathrm{d} t
$$

The thermal energy of the water flowing through the outlet section $\mathrm{W}_{2}$ is

$$
\mathrm{d} Q_{\mathrm{W}_{2}}=c_{\mathrm{w}} \rho_{\mathrm{w}} T_{\mathrm{W}_{2}} q_{\mathrm{w}} \mathrm{d} t
$$

where $q_{\mathrm{w}}$ is the flow rate of the cooling water, $c_{\mathrm{w}}$ is the specific heat of the cooling water, $\rho_{\mathrm{W}}$ is the density of the cooling water, and $T_{\mathrm{W}_{1}}$ and $T_{\mathrm{W}_{2}}$ are the inlet and outlet water temperatures, respectively.

The change in thermal energy in the water pipe between sections $W_{1}$ and $W_{2}$ is

$$
\mathrm{d} Q_{\mathrm{W}}=\int_{\mathrm{W}_{1}}^{\mathrm{W}_{2}} c_{\mathrm{w}} \rho_{\mathrm{W}}\left(\frac{\partial T_{\mathrm{W}_{p}}}{\partial t} \mathrm{~d} t\right) \cdot A_{p} d l
$$

where $A_{p}$ is the area of the pipe section, $T_{\mathrm{W}_{p}}$ is the water temperature between the sections, and $d l$ is the distance between sections $\mathrm{W}_{1}$ and $\mathrm{W}_{2}$.

At thermal equilibrium, we have

$$
\mathrm{dQ}_{\mathrm{W}_{2}}=\mathrm{d} Q_{\mathrm{W}_{1}}+\mathrm{d} Q_{c}-\mathrm{d} Q_{\mathrm{W}}
$$

Substituting Eqs. (1)-(4) into Eq. (5), the increase in water temperature between sections $W_{1}$ and $W_{2}$ may be expressed as

$$
\begin{aligned}
\Delta T_{\mathrm{W}} & =\Delta T_{\mathrm{W}_{2}}-\Delta T_{\mathrm{W}_{1}} \\
& =\frac{-\lambda}{c_{\mathrm{w}} \rho_{\mathrm{w}} q_{\mathrm{w}}} \iint_{\Gamma^{0}} \frac{\partial T}{\partial n} \mathrm{~d} s+\frac{1}{q_{\mathrm{w}}} \int \frac{\partial T_{\mathrm{W}_{p}}}{\partial t} \mathrm{~d} v
\end{aligned}
$$

Considering that both the volume and the temperature increases of water are very small within $d l$, Eq. (6) can be simplified as follows:

$$
\Delta T_{\mathrm{W}}=\frac{-\lambda}{c_{\mathrm{w}} \rho_{\mathrm{w}} q_{\mathrm{w}}} \iint_{\Gamma^{0}} \frac{\partial T}{\partial n} \mathrm{ds}
$$

where the surface integral $\iint_{\Gamma^{0}}(\partial T / \partial n) \mathrm{d}$ s can be directly obtained by Gaussian numerical integration over the boundary of the concrete elements on the outer edge of the water pipe.

Assuming that the water temperature $T_{\mathrm{W}_{0}}$ at the inlet is known, we can calculate the water temperature at any section $\mathrm{W}_{i}$ by dividing the pipe into $m$ sections and summing the temperature increase along the pipe as follows:

$$
T_{\mathrm{W}_{i}}=T_{\mathrm{W}_{0}}+\sum_{j=1}^{i} \Delta T_{\mathrm{W}_{j}}, \quad i=1,2,3, \cdots, m
$$

Equation (7) shows that the change in water temperature along the water pipe is related to the temperature gradient $\partial T / \partial n$, which constitutes a nonlinear boundary problem. Thus, the temperature field of the water pipe cannot be obtained in a single step, so we adopt an iterative algorithm to solve this nonlinear boundary problem.

The finite element control equation for calculating the transient temperature field is available from the study by Zhu [1]. In the present work, we use Visual Fortran to develop the water-pipe-cooling FEM simulation program [25].

\section{Optimization Principle for Calculating Position of Buried Thermometer}

Assuming that the temperature-control process line represents the average-temperature history of the concrete pouring 


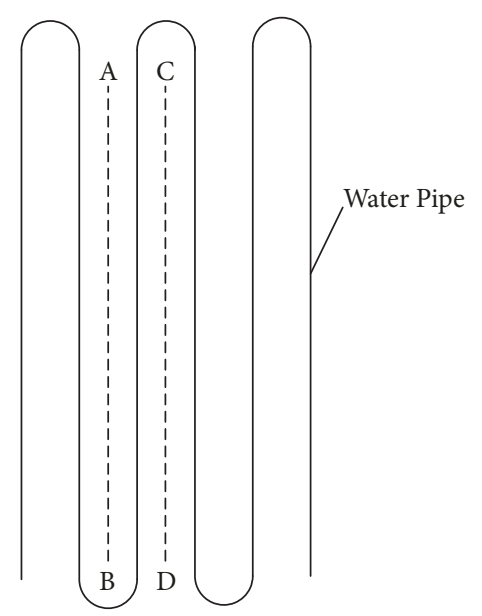

Figure 3: Typical layout of cooling pipe.

block, we adopt the following method to determine with the reasonable geometric position of the buried thermometers. First, we must obtain the average-temperature history of the concrete pouring block embedded with cooling pipes, and then we have to find the geometric position $\left(x^{*}, y^{*}, z^{*}\right)$ whose temperature history most closely matches the averagetemperature history of the concrete pouring block. By burying the thermometers at the positions $\left(x^{*}, y^{*}, z^{*}\right)$ in the concrete pouring block, the measured temperature will better reflect the temperature of the concrete pouring block. That is, the position of the buried thermometers is a geometric position uncertainty problem, which can be solved by an optimization algorithm.

(1) Average Temperature of the Concrete Pouring Block. The water-pipe-cooling FEM is used to simulate the temperature field of the concrete pouring block cooled by water, and the average temperature $T_{\text {ave }}(t)$ of the concrete pouring block at time $t$ is

$$
T_{\text {ave }}(t)=\frac{\sum_{\mathrm{e}}\left(\sum_{\mathrm{g}} T_{\mathrm{g}}(t) \cdot V_{\mathrm{g}}\right)}{\sum_{\mathrm{e}}\left(\sum_{\mathrm{g}} V_{\mathrm{g}}\right)}
$$

where $T_{\mathrm{g}}(t)\left[{ }^{\circ} \mathrm{C}\right]$ is the temperature of the elemental Gauss point at time $t, V_{\mathrm{g}}\left[\mathrm{m}^{3}\right]$ is the volume of the elemental Gauss point, $\sum_{\mathrm{g}}$ is the accumulation of the elemental Gauss points, $\sum_{\mathrm{e}}$ is the accumulation of the pouring block units, and $\sum_{\mathrm{e}}\left(\sum_{\mathrm{g}} V_{\mathrm{g}}\right)\left[\mathrm{m}^{3}\right]$ is the volume of the concrete pouring block that removes the volume occupied by the water pipe.

(2) Temperature of an Arbitrary Point in the Concrete Pouring Block. The temperature $T(x, y, z, t)$ of an arbitrary point in the concrete pouring block at time $t$ is

$$
T(x, y, z, t)=\sum_{i} N_{i}(x, y, z) \cdot T_{i}(t)
$$

where $N_{i}(x, y, z)$ is the shape function, and $T_{i}(t)\left[{ }^{\circ} \mathrm{C}\right]$ is the temperature of node $i$ at time $t$.

(3) Mathematical Model to Optimize the Position of Buried Thermometers. Based on the average-temperature history of the concrete pouring block and the temperature at an arbitrary point in the concrete pouring block, we establish the following mathematical model:

$$
\begin{array}{ll}
\min & f(X)=\frac{1}{n} \sum_{j=1}^{n}\left(T_{\mathrm{ave}}\left(t_{j}\right)-T\left(x, y, z, t_{j}\right)\right)^{2} \\
\text { s.t. } & x_{\min } \leq x \leq x_{\max } \\
& y_{\min } \leq y \leq y_{\max } \\
& z_{\min } \leq z \leq z_{\max }
\end{array}
$$

where $X=[x, y, z]$ is the geometric position of the arbitrary point in the concrete pouring block, $T_{\text {ave }}\left(t_{j}\right)\left[{ }^{\circ} \mathrm{C}\right]$ is the average temperature of concrete pouring block at time $t_{j}$, $T\left(x, y, z, t_{j}\right)\left[{ }^{\circ} \mathrm{C}\right]$ is the temperature at the arbitrary point in the concrete pouring block at time $t_{j}$, and $x_{\min }, x_{\max }, y_{\min }$, $y_{\max }, z_{\min }$, and $z_{\max }$ are the upper and lower limits of the $x$, $y$, and $z$ coordinates, respectively.

The constrained optimization method, such as complex method, is used to solve Eq. (11) and obtain the optimal position of the buried thermometers.

\section{(4) Steps to Optimize the Position of the Buried Thermometers}

Step 1. As shown in Figure 3, the cooling pipes embedded in the concrete pouring block are generally arranged in a serpentine layout. Since the $\mathrm{AB}$ and $\mathrm{CD}$ faces along the direction of the water flow are approximately symmetric, we assume that they form an adiabatic boundary. In this work, we selected a concrete pouring block embedded with cooling pipes and built a three-dimensional simulation model (see Figure 4). We consider cement hydration heat release and water-pipe cooling, and by using the water-pipe-cooling FEM, we obtain the temperature field of the concrete model 


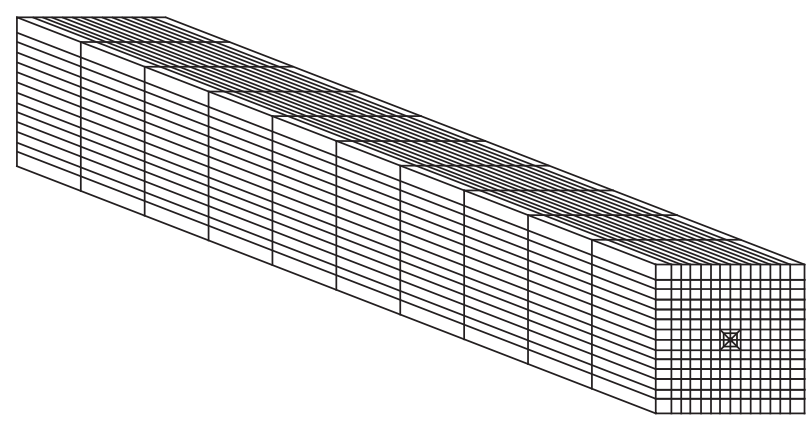

FIGURE 4: Model of concrete embedded with cooling pipe.

embedded with cooling pipes. In addition, we use Eq. (9) to calculate the average-temperature history of the concrete model embedded with cooling pipes.

Step 2. To achieve uniform cooling, the flowing direction of the cooling water usually changes at regular intervals in the concrete model. By using the symmetry of the temperature field of the concrete model embedded with cooling pipes, we analyze the temperature field of the intermediate section of the concrete model. From the node temperature of the elements in the intermediate section, the temperature at an arbitrary point of the section is given by Eq. (10). Therein, because the node temperatures in the intermediate section are analyzed, the temperature $\mathrm{T}(x, y, z, t)$ in Eq. (10) is simplified as $\mathrm{T}(x, y, t)$.

Step 3. By using the average-temperature history calculated in Step 1 and the temperature at the arbitrary point obtained in Step 2, we established the mathematical model by using Eq. (11).

Step 4. By using the optimization algorithm to solve the mathematical model for the position of the buried thermometers [Eq. (11)], we obtain the optimal position at which to bury thermometers in the concrete pouring block.

\section{Case Analysis}

According to previous engineering experience [1], the spacing between water pipes embedded in a concrete dam is usually $1.5-3.0 \mathrm{~m}$. In this work, the adiabatic temperature rise of concrete adopts a exponential expression of $\theta(\tau)=25.3[1-$ $\exp (-0.315 \tau)$ ], in units of ${ }^{\circ} \mathrm{C}$, the thermal conductivity of concrete is $\lambda=8.49 \mathrm{~kJ} /\left(\mathrm{m} \cdot \mathrm{h} \cdot{ }^{\circ} \mathrm{C}\right)$, the specific heat of concrete is $c=0.995 \mathrm{~kJ} /\left(\mathrm{kg} \cdot{ }^{\circ} \mathrm{C}\right)$, the density of concrete is $\rho=$ $2400 \mathrm{~kg} / \mathrm{m}^{3}$, the water flow in the pipes is $24 \mathrm{~m}^{3}$ per day based on engineering practices, the specific heat of water is $c_{\mathrm{w}}=$ $4.187 \mathrm{~kJ} /\left(\mathrm{kg} \cdot{ }^{\circ} \mathrm{C}\right)$, and the density of water is $\rho_{\mathrm{w}}=1000 \mathrm{~kg} / \mathrm{m}^{3}$.

4.1. Establishment of Concrete Model and Numerical Simulation. In practical concrete dam engineering, the cooling pipes embedded into concrete pouring blocks generally arrange in a serpentine layout. Zhu and Cai [8] found that the average temperature difference between a serpentine water pipe and a straight pipe of the same length when both sides of the concrete prisms are insulated is small. Therefore, in the present case, to simplify the calculation, we assume the serpentine-shaped water pipe as straight, adjacent water pipes. In this case, the length of the concrete prism is $L=$ $100 \mathrm{~m}$ and, according to the spacing between water pipes in practical concrete projects, we designed four prisms with different cross-sectional dimensions (width $\times$ height): $1.0 \mathrm{~m} \times$ $1.0 \mathrm{~m}, 1.5 \mathrm{~m} \times 1.5 \mathrm{~m}, 1.0 \mathrm{~m} \times 1.5 \mathrm{~m}, 2.0 \mathrm{~m} \times 1.5 \mathrm{~m}$. At the center of each concrete prism, we arrange a cooling-water pipe with an outer diameter of $\phi=32 \mathrm{~mm}$.

The finite-element simulation model is meshed using three-dimensional hexahedron 8-node isoparametric elements. When simulating the temperature field, we assume that the six surfaces of the concrete prism are adiabatic boundaries, and we set the initial temperature of the concrete and the inlet temperature of the cooling water both to $10^{\circ} \mathrm{C}$. When using the water-pipe-cooling FEM to simulate the temperature field during the cooling period, the start time of water flow is day 1 , the water flows for 10 days, and the time step is the 0.1 day. Figure 5 shows the average-temperature process line in the concrete prisms during the cooling period calculated by using Eq. (9).

4.2. Analysis of Average Temperature of Pouring Block at Different Times Based on Isotherm. To achieve uniform cooling, the flow direction of the cooling water changes at regular intervals in the concrete model. When assuming that the six surfaces of the concrete prism are adiabatic boundaries, the temperature of the intermediate section of the concrete prism does not depend substantially on the flow direction of the cooling water but only changes due to the cement hydration. According to the symmetry of the concrete prism, the temperature fields of the intermediate section of the concrete model are analyzed. Thus, we first obtain the temperature surface of the intermediate section of the concrete prism at a given time; in addition, the average temperature of the concrete prisms during the cooling period at a given time is called the "isothermal value," and then we find the geometric position of the isotherm on the temperature surface. Specifically, we use the built-in function griddata of MATLAB (version R2014b) to obtain the temperature surface of the intermediate section at different times by biharmonic spline interpolation. Next, the average temperature $T_{\text {ave }}(t)$ 


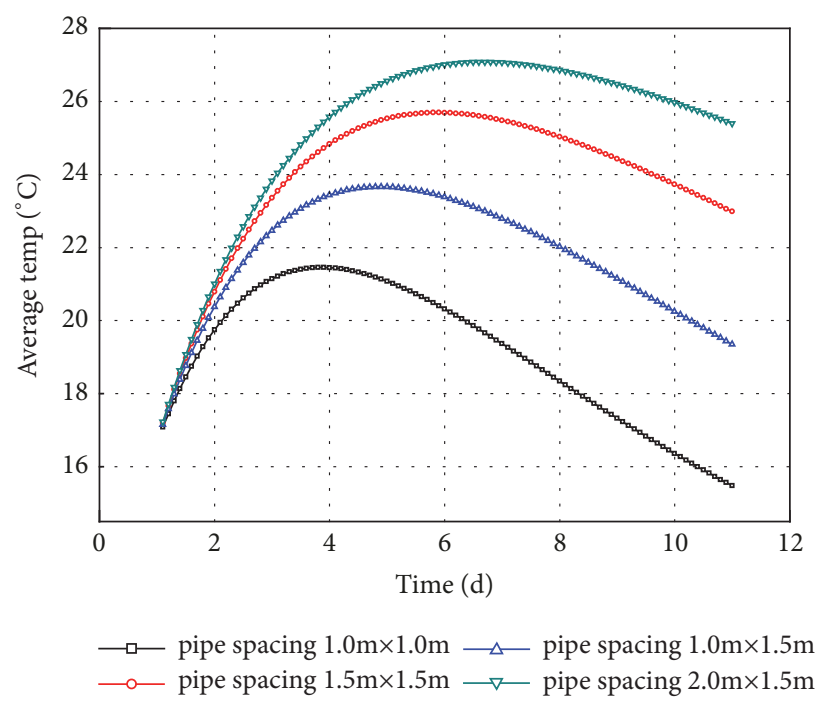

FIGURE 5: Average-temperature process line of concrete prisms for four water-pipe spacing cases.

of the concrete prism at different times (shown in Figure 5) is set as the isothermal value, and we get the isothermal curve corresponding to each isothermal value by using the built-in function contour3 of MATLAB. In this way, we obtain the position of the average temperature of the concrete pouring block at time $t$. For example, Figure 6 shows the temperature surfaces and the isotherms for the intermediate sections under four different water-pipe spacing cases at $t=2$ days (after the cooling water has flowed for 1 day). Figure 7 shows 100 isotherms under four different water pipe spacing cases, all calculated for the water-flow period (day 1 to day 11).

Figures 6 and 7 reveal the following information:

(1) When the average temperature of the concrete pouring block is set as the isothermal value, the isotherms in the intermediate sections curve and the geometric position of the isotherms in the intermediate sections change with time over a certain range. With increasing cooling time, the geometric position of the isotherms gradually stabilizes until it remains constant.

(2) When the cross-sectional dimensions are $1.0 \mathrm{~m} \times 1.0 \mathrm{~m}$ and $1.5 \mathrm{~m} \times 1.5 \mathrm{~m}$, the geometric positions of the isotherms in the intermediate sections change little and are approximately circular.

(3) When the cross-sectional dimensions are $1.0 \mathrm{~m} \times 1.5$ $\mathrm{m}$ and $2.0 \mathrm{~m} \times 1.5 \mathrm{~m}$, the geometric positions of the isotherms in the intermediate sections change significantly, although gradually, from the initial elliptical distribution to a parabolic distribution.

\subsection{Establishment of Optimization Model for Position of} Buried Thermometer. Figure 7 shows that, when the average temperature of the concrete pouring block is set as the isothermal value, the geometric position of the isotherm in the intermediate section is distributed over a curve, and the isotherms change with time over a certain range. Therefore, by using the mathematical model (11), we obtain the geometric position of the isotherms closest to the averagetemperature history of the concrete pouring block on the intermediate sections.

(1) Temperature of Arbitrary Point in Concrete Pouring Block. According to the symmetry of a concrete prism, we use the intermediate sections of the concrete prisms to calculate and analyze the temperature of an arbitrary point in the concrete pouring block. Because the six surfaces of the concrete prism are assumed to be adiabatic, the temperature field in the intermediate section of the concrete prism is symmetric, so we analyze the temperature of a quarter of the intermediate sections, as shown in Figure 8. Although the concrete prisms were meshed by hexahedron 8-node isoparametric elements, the intermediate sections were presented by quadrilateral 4node isoparametric elements, as shown in Figure 9.

For an arbitrary point in the element of a quarter of the intermediate section, the temperature of this point can be calculated by the node temperature and shape function [26] in the $\xi-\eta$ local-coordinate system:

$$
\begin{aligned}
T(\xi, \eta, t)=\sum_{i=1}^{4} N_{i}(\xi, \eta) T_{i}(t) & \\
& -1 \leq \xi \leq 1, \quad-1 \leq \eta \leq 1
\end{aligned}
$$

where $T_{i}(t)$ is the temperature of node $i$ at time $t, N_{i}(\xi, \eta)$ is the shape function of the quadrilateral 4 -node isoparametric element, and $N_{i}(\xi, \eta)=(1 / 4)\left(1+\xi_{i} \xi\right)\left(1+\eta_{i} \eta\right)(i=1,2,3,4)$.

(2) Mathematical Model to Optimize Position of Buried Thermometer. Figure 7 reveals that the isotherms pass through many possible elements for above four different waterpipe spacing cases. Therefore, by optimizing these possible elements one by one, we can determine the optimal geometric position of the thermometers buried in the intermediate section. The temperature history at multiple locations on each possible element approaches the average-temperature 


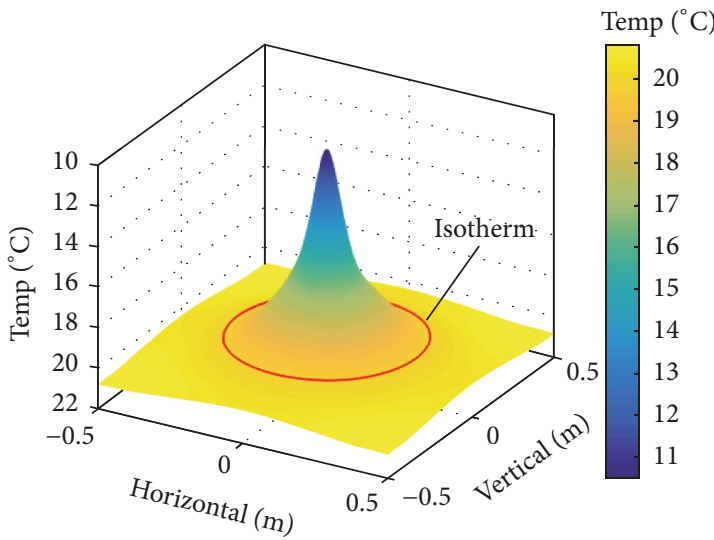

(a) Pipe spacing $1.0 \mathrm{~m} \times 1.0 \mathrm{~m}$

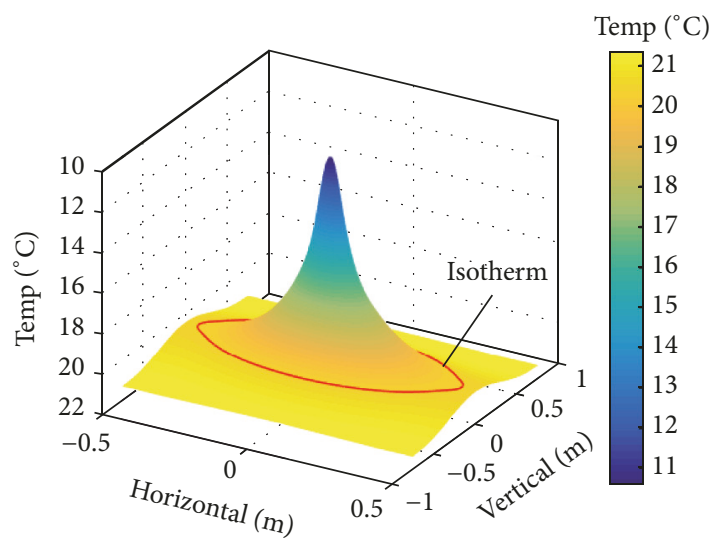

(c) Pipe spacing $1.0 \mathrm{~m} \times 1.5 \mathrm{~m}$

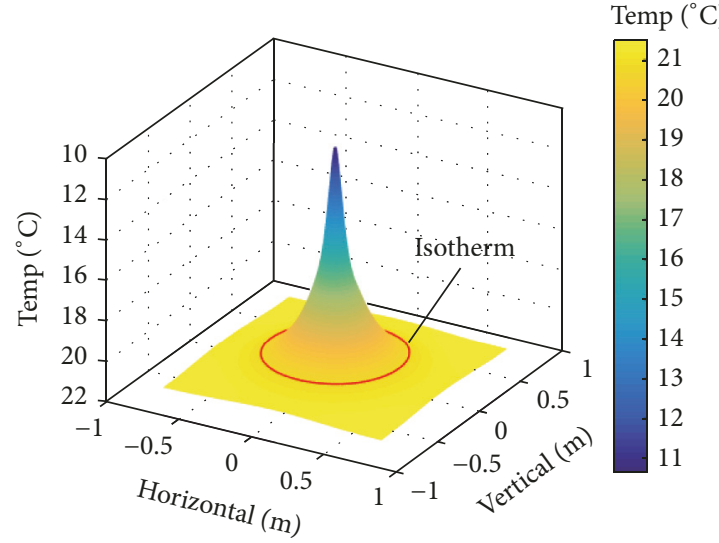

(b) Pipe spacing $1.5 \mathrm{~m} \times 1.5 \mathrm{~m}$

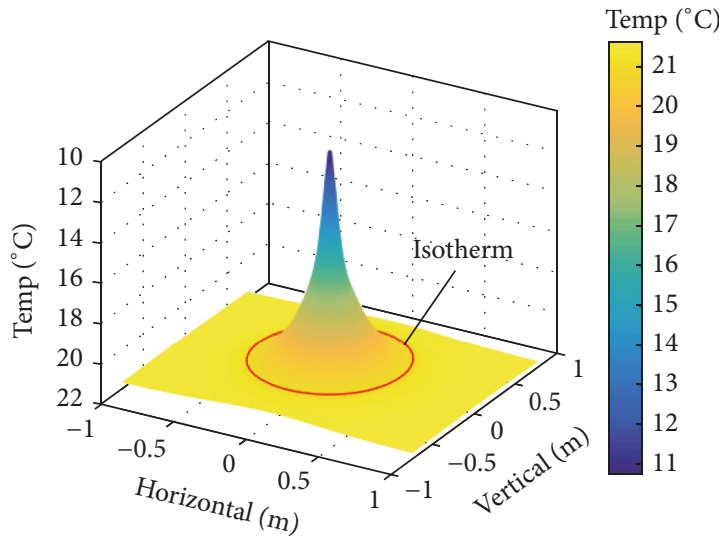

(d) Pipe spacing $2.0 \mathrm{~m} \times 1.5 \mathrm{~m}$

FIgURE 6: Temperature surfaces and isotherms for intermediate sections for four different water-pipe spacing cases at $t=$ day 2.

history of the concrete pouring block. To solve this issue, when optimizing these possible elements one by one, we fix $\eta$ to $\eta=-1.0,-0.9, \ldots, 0, \ldots, 0.9,1.0$ and then use the onedimensional search algorithm to optimize $\xi$ in the $\xi-\eta$ localcoordinate system. In the calculation, the temperature of an arbitrary point in these possible elements of a quarter of the intermediate section can be obtained by using Eq. (12). Eq. (11) of mathematical model is then simplified as follows:

$$
\begin{array}{ll}
\min & f(\xi)=\frac{1}{n} \sum_{j=1}^{n}\left[T_{\text {ave }}\left(t_{j}\right)-\sum_{i=1}^{4} N_{i}(\xi, \eta) T_{i}\left(t_{j}\right)\right]^{2} \\
\text { s.t. } & -1 \leq \xi \leq 1
\end{array}
$$

where $n$ is determined by the time step of the temperaturefield calculation. In this simulation, the time step for days 1-11 is the 0.1 day, so $n=100$.

When these above possible elements are optimized one by one based on Eq. (13), the corresponding $\xi$ that gives Eq. (13) a solution does not necessarily exist. Therefore, we adopt for the calculation the double-optimized control criteria of minimum error and maximum number of optimizations, and the minimum error and maximum number of optimizations are $10^{-6}$ and 100 , respectively. Since the objective function $f(\xi)$ is a unimodal function on the interval $\xi \in[-1,1]$, the solution obtained by the method of bisection is the global optimal solution.

\subsection{Solution of Optimization Model for Position of Buried} Thermometer. By using the method of bisection, which is a one-dimensional search algorithm, to solve Eq. (13), we obtain $\xi-\eta$, and the corresponding coordinates $x-y$ may be calculated from the following coordinate-conversion equation:

$$
\begin{aligned}
& x=\sum_{i=1}^{4} N_{i}(\xi, \eta) x_{i} \\
& y=\sum_{i=1}^{4} N_{i}(\xi, \eta) y_{i}
\end{aligned}
$$

where $x_{i}$ and $y_{i}$ are the coordinates of node $i$ in the $x-y$ coordinate system.

In the above analysis, the optimal positions of the buried thermometer in a quarter of the intermediate sections are calculated. Once the optimized position of the buried thermometer is obtained for the quarter section, it may be obtained for the total intermediate section based on the 


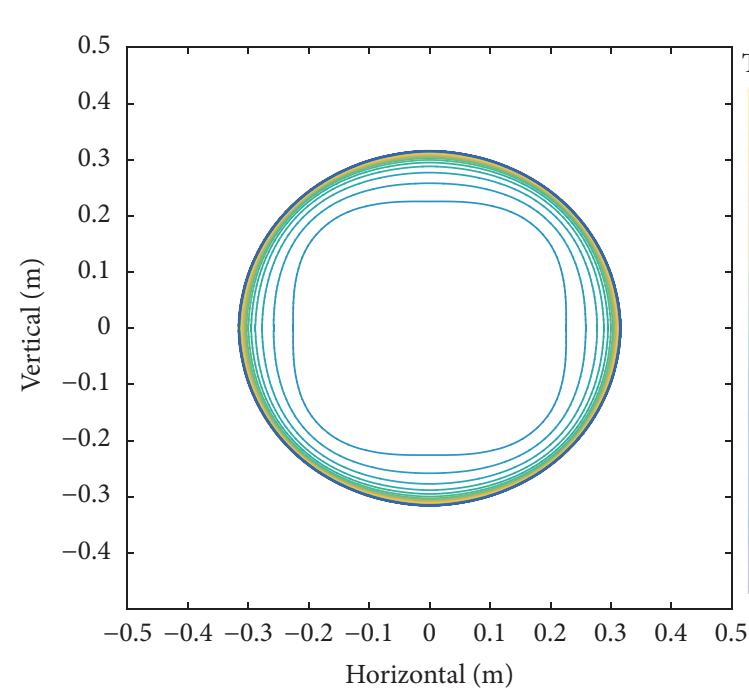

(a) Pipe spacing $1.0 \mathrm{~m} \times 1.0 \mathrm{~m}$

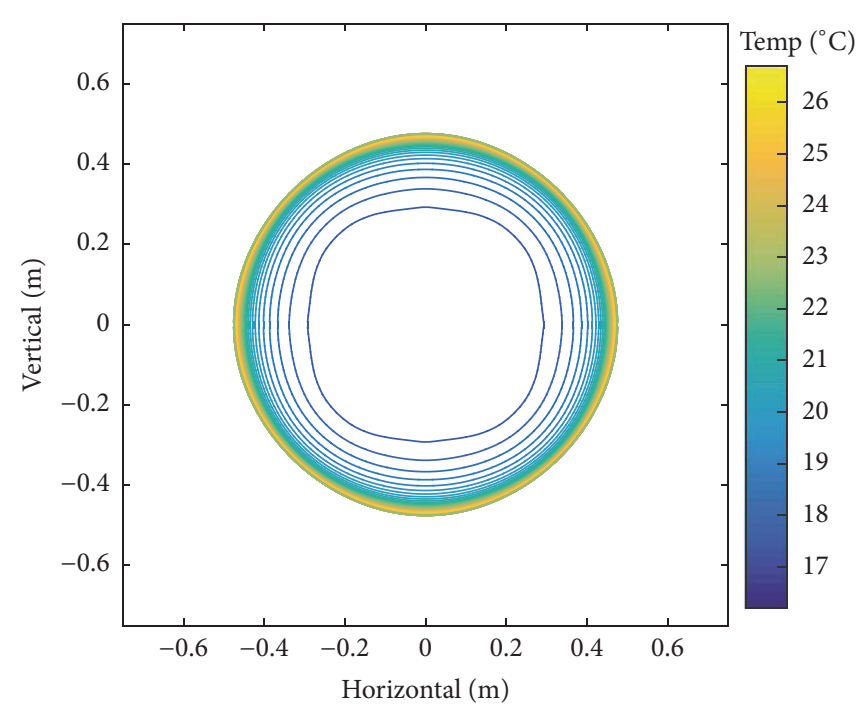

(b) Pipe spacing $1.5 \mathrm{~m} \times 1.5 \mathrm{~m}$

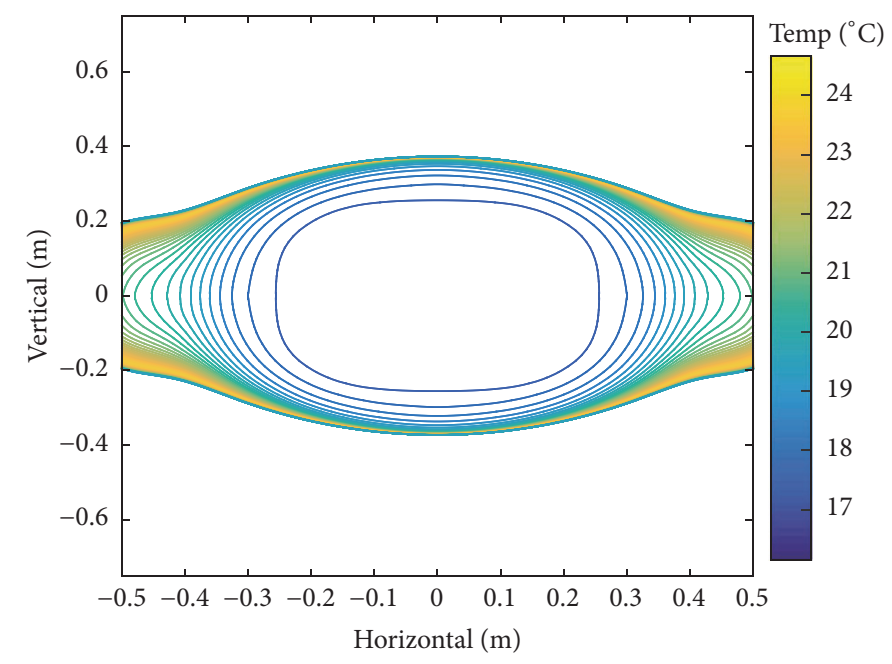

(c) Pipe spacing $1.0 \mathrm{~m} \times 1.5 \mathrm{~m}$

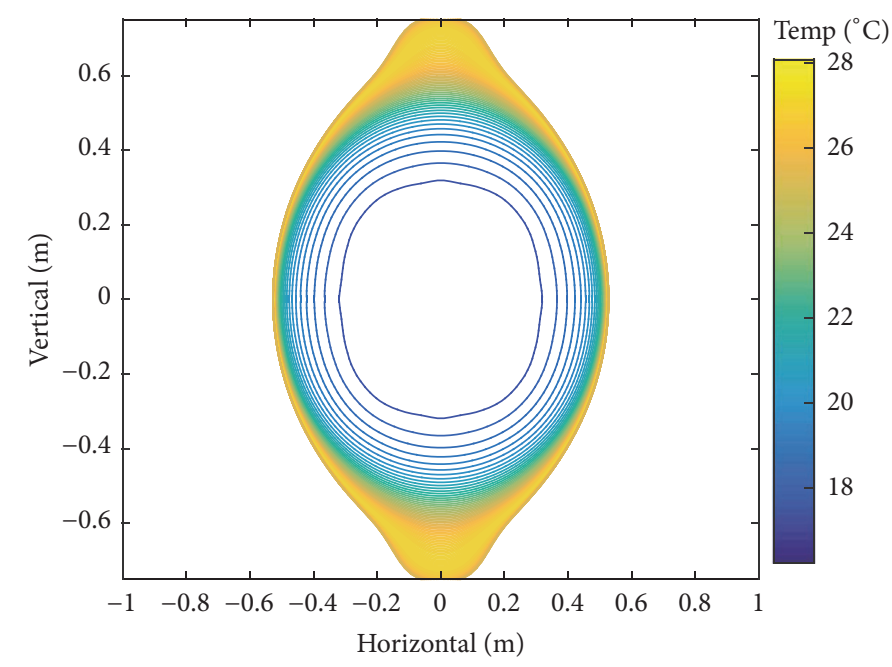

(d) Pipe spacing $2.0 \mathrm{~m} \times 1.5 \mathrm{~m}$

FIGURE 7: Distribution of geometric position of average temperature of intermediate sections for four different water-pipe spacing cases. 


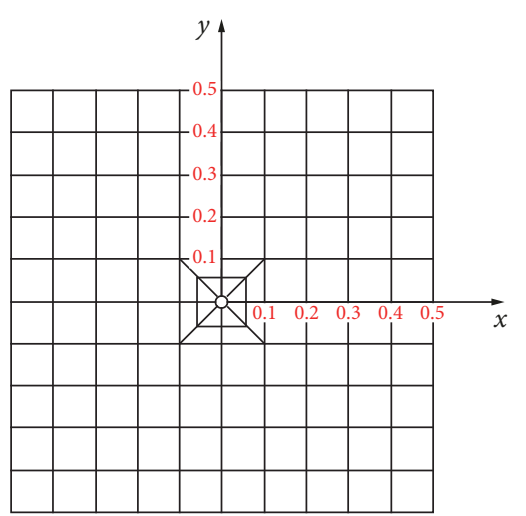

(a) Pipe spacing $1.0 \mathrm{~m} \times 1.0 \mathrm{~m}$

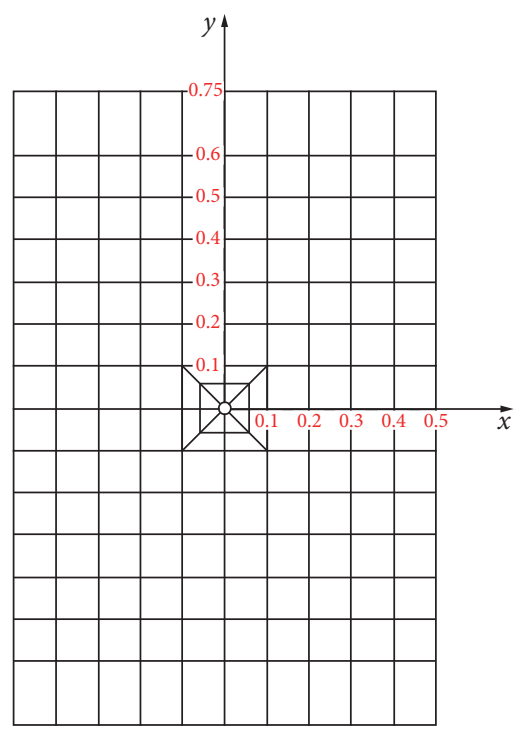

(c) Pipe spacing $1.0 \mathrm{~m} \times 1.5 \mathrm{~m}$

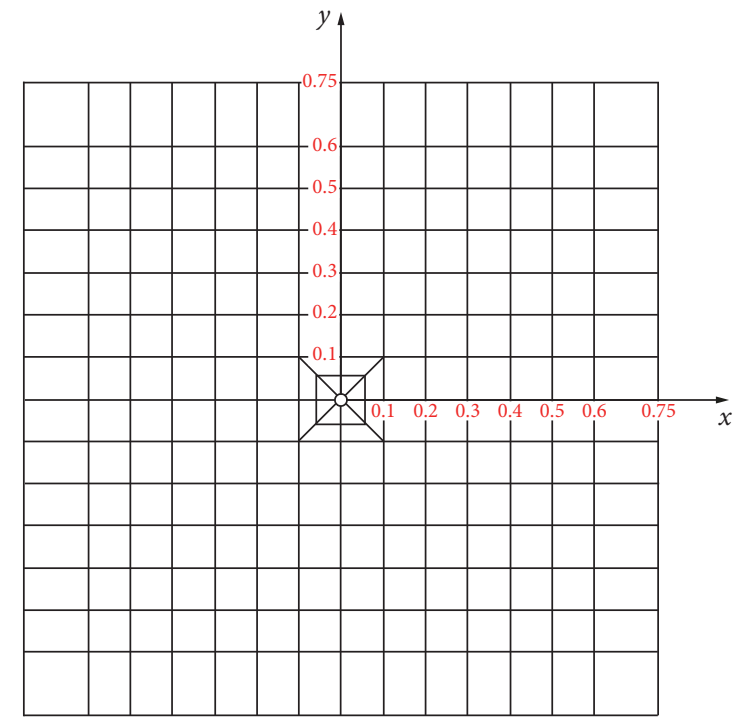

(b) Pipe spacing $1.5 \mathrm{~m} \times 1.5 \mathrm{~m}$

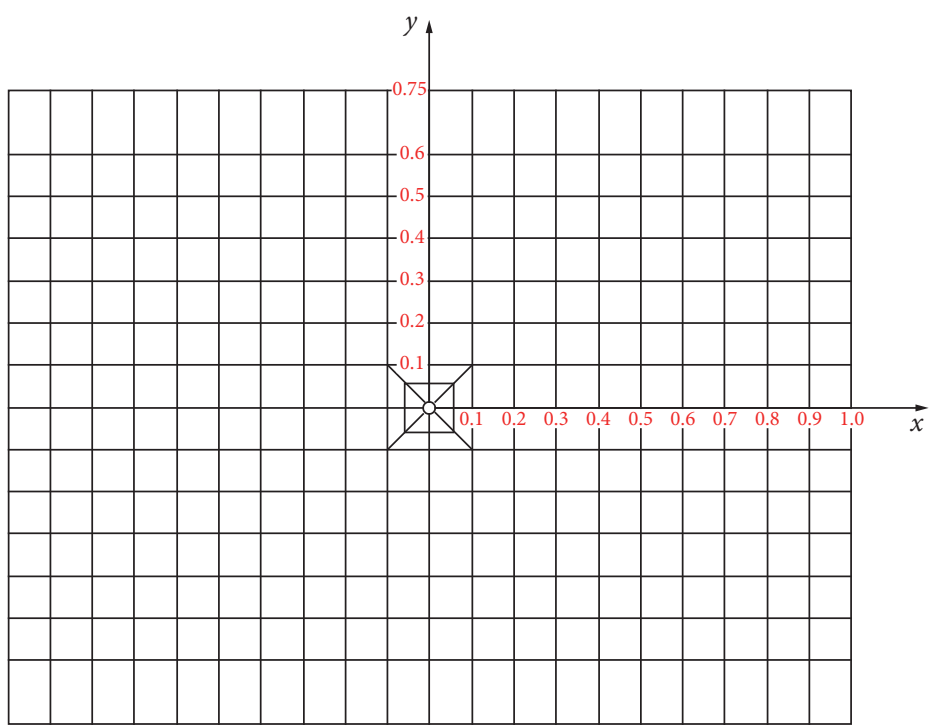

(d) Pipe spacing $2.0 \mathrm{~m} \times 1.5 \mathrm{~m}$

FIGURE 8: Meshing of intermediate sections for four different water-pipe spacing cases.

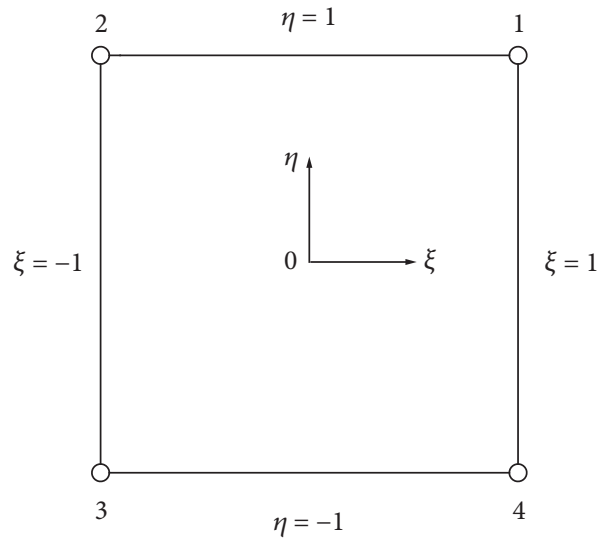

FIGURE 9: Quadrilateral 4-node element. 


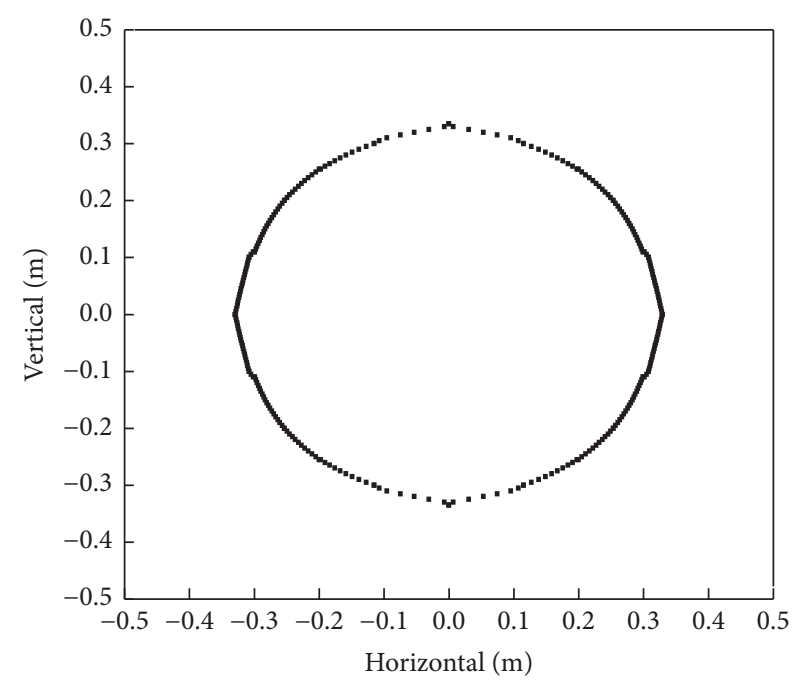

(a) Pipe spacing $1.0 \mathrm{~m} \times 1.0 \mathrm{~m}$

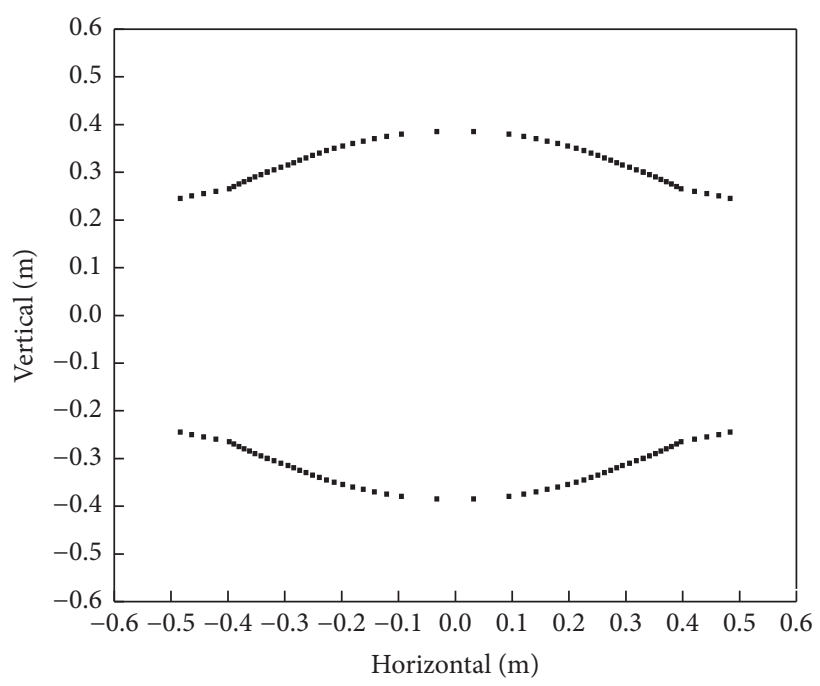

(c) Pipe spacing $1.0 \mathrm{~m} \times 1.5 \mathrm{~m}$

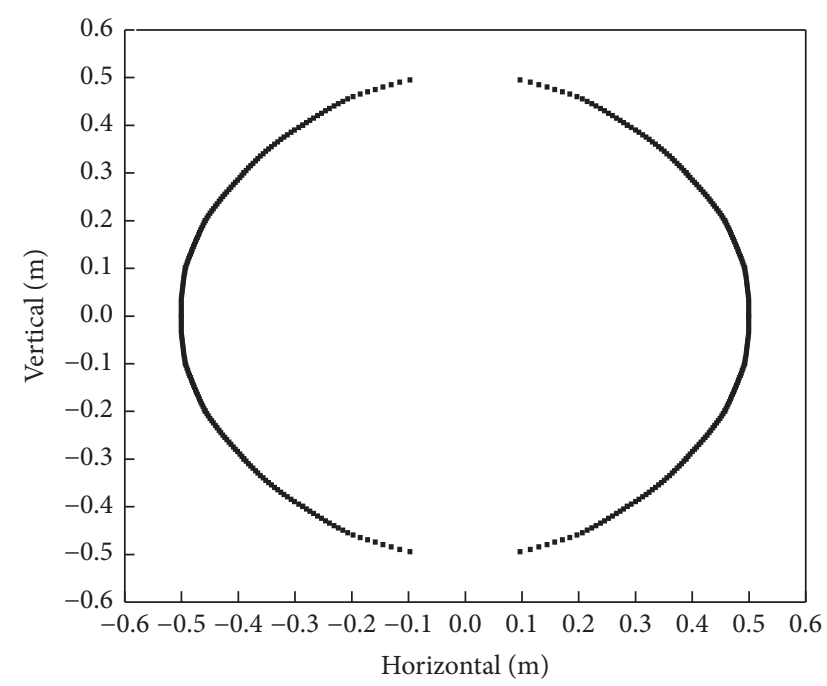

(b) Pipe spacing $1.5 \mathrm{~m} \times 1.5 \mathrm{~m}$

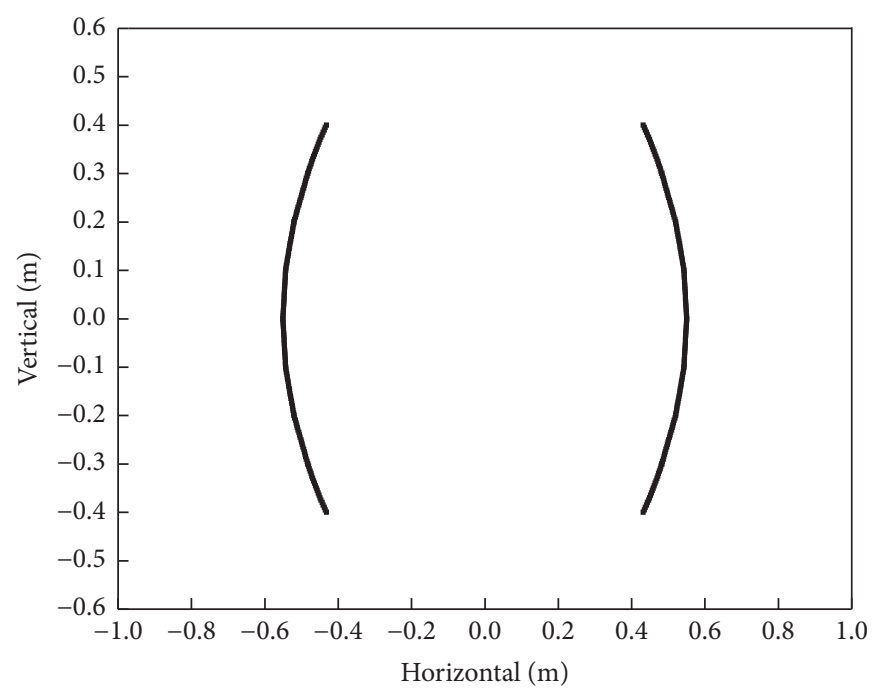

(d) Pipe spacing $2.0 \mathrm{~m} \times 1.5 \mathrm{~m}$

FIGURE 10: Optimized position of the buried thermometer for four different water-pipe spacing cases.

symmetry. Figure 10 shows the optimized positions for the buried thermometer for above four different cross-sectional dimensions.

The geometric positions of the isotherms that correspond to the average temperature at different times (see Figure 7) and the geometric position of the thermometers obtained by the optimization model (see Figure 10) lead to the following conclusions:

(1) The analysis of four different water-pipe-spacing cases shows that the optimal position of the buried thermometer obtained from the mathematical model is similar to the geometric position of the isotherms based on the average temperature of the concrete pouring block at different times. The analysis result also shows that the mathematical model for determining the position of the buried thermometer adequately reflects the distribution of the average temperature in the intermediate section.
(2) For cross-sectional dimensions of $1.0 \mathrm{~m} \times 1.0 \mathrm{~m}$ and $1.5 \mathrm{~m} \times 1.5 \mathrm{~m}$ (i.e., equal distance between the horizontal and vertical water pipes), both the geometric position of the isotherms based on the average temperature of the concrete pouring block and the optimized position of the buried thermometer obtained from the mathematical model are approximately circular. For these two water-pipe spacing cases, the distances between the optimized geometric position of the buried thermometer and the center of the water pipe are both about 0.3 times the length of the side of the cross section.

(3) When the cross-sectional dimensions are $1.0 \mathrm{~m} \times$ $1.5 \mathrm{~m}$ and $2.0 \mathrm{~m} \times 1.5 \mathrm{~m}$ (i.e., unequal distance between the horizontal and vertical water pipes), both the geometric position of the isotherms based on the average temperature of the concrete pouring block and the optimized position of the buried thermometer obtained from the mathematical 


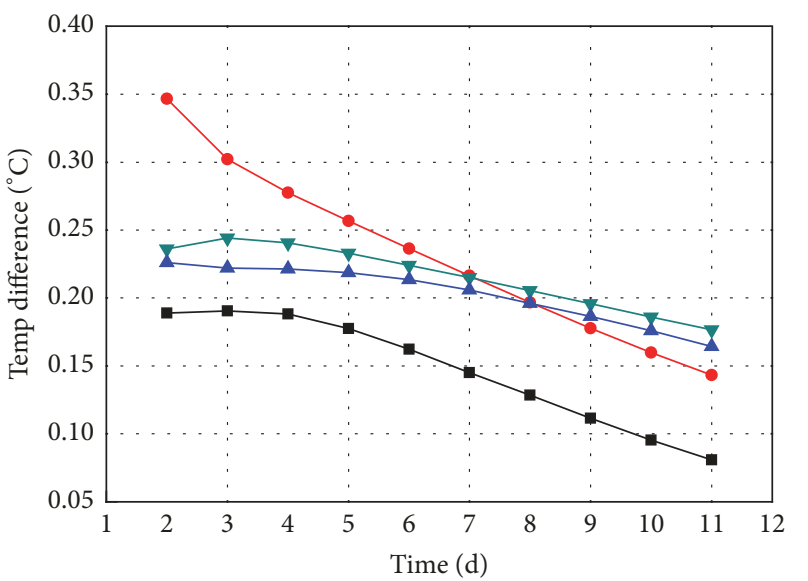

$\longrightarrow$ pipe spacing $1.0 \mathrm{~m} \times 1.0 \mathrm{~m} \_$pipe spacing $1.5 \mathrm{~m} \times 1.5 \mathrm{~m}$

(a) Temperature difference at the farthest point

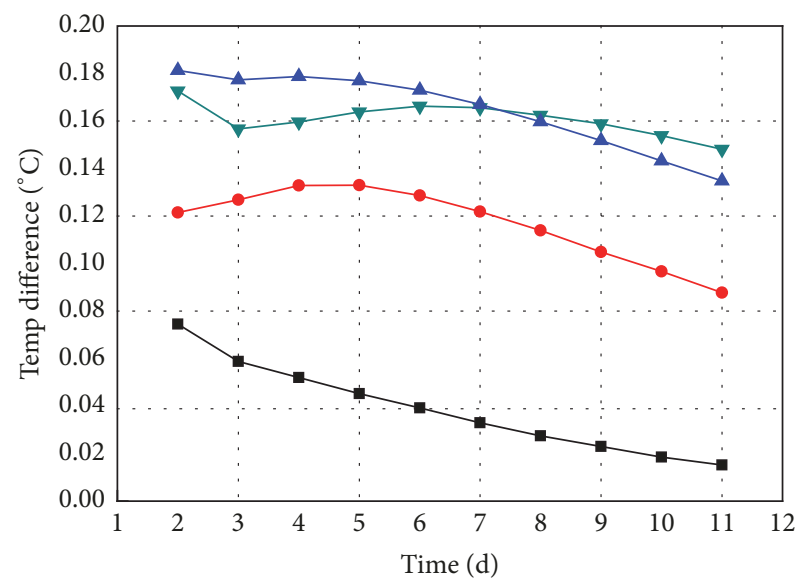

$\rightarrow$ pipe spacing $1.0 \mathrm{~m} \times 1.0 \mathrm{~m} \_$pipe spacing $1.5 \mathrm{~m} \times 1.5 \mathrm{~m}$

(b) Temperature difference at the nearest point

FIGURE 11: Temperature difference between average temperature and (a) the farthest point and (b) the nearest points.

model are approximately parabolic. For these two water-pipe spacing cases, the distances between the optimized geometric position of the thermometer and the center of the water pipe are both about 0.25 times the length of the long side of the cross-section.

\subsection{Evaluation of Optimized Position of Buried Thermometer.} Figures 11(a) and 11(b) show the temperature difference during the water-cooling period between the farthest (nearest) point and the average temperature of the concrete pouring block.

Figure 11 shows that the temperature difference between the average temperature of the concrete pouring block and the temperature at the optimized thermometer position decreases upon increasing the water-cooling time. The maximum temperature difference is less than $0.35^{\circ} \mathrm{C}$ for the farthest point for pipe spacing $1.0 \mathrm{~m} \times 1.5 \mathrm{~m}$ and $0.18^{\circ} \mathrm{C}$ for the nearest point for pipe spacing $1.5 \mathrm{~m} \times 1.5 \mathrm{~m}$. These results show that any of the optimal positions obtained by the optimization model accurately reflects the average temperature history of the concrete pouring block. By burying thermometers at these positions, the measured temperature can better characterize the average-temperature history of the concrete pouring block.

\section{Conclusions}

To reduce the uncertainty in the position of the buried thermometer in a concrete pouring block, we develop a mathematical model to optimize the position. We use the optimization algorithm to obtain the geometric positions of thermometers buried in the concrete pouring block for four different water-pipe spacing cases. The results lead to the following conclusions:
(1) The temperature field of the concrete pouring block during the cooling period is so complicated that the measured temperature is too low (high) if the thermometer is positioned too close to (too far from) a water pipe. When the average temperature of the concrete pouring block is set as the isothermal value, the isotherms on the intermediate sections form curves, and the geometric positions of the isotherms in the intermediate sections change over time within a certain range. However, with increasing cooling time, the geometric position of the isotherms gradually stabilizes and becomes constant.

(2) Exploiting the symmetry of a concrete prism, we use the intermediate sections of the concrete prisms to calculate and analyze the temperature of an arbitrary point in the concrete pouring block. Since the temperature history at multiple locations in each possible element approaches the average-temperature history of the concrete pouring block, the possible elements are optimized one by one. Next, based on the average-temperature history of the concrete pouring block and the temperature history of the arbitrary point in the given element, we build a mathematical model to obtain the geometric position of the thermometer and use a one-dimensional search algorithm to solve the mathematical model. By analyzing different cases, we find this method to be feasible for determining the optimum position of a thermometer buried in a concrete pouring block.

(3) For equal distances between the horizontal and vertical water pipes, both the geometric position of the isotherms based on the average temperature of the concrete pouring block and the optimized position of the buried thermometer obtained from the mathematical model are approximately circular. For these two water-pipe spacing cases, the distances between the optimized geometric position of the thermometer and the center of the water pipe are both about 0.3 times the length of the side of the cross-section. For unequal distances between the horizontal and vertical water pipes, 
both the geometric position of the isotherms based on the average temperature of the concrete pouring block and the optimized position of the buried thermometer obtained from the mathematical model are approximately parabolic. For these two water-pipe spacing cases, the distances between the optimized geometric position of the thermometer and the center of the water pipe are both about 0.25 times the length of the long side of the cross-section.

\section{Data Availability}

The data in this article were calculated and analyzed by the authors. The data for Figures 5, 7, and 10 are presented in Supplementary Materials with excel files.

\section{Conflicts of Interest}

The authors declare that they have no conflicts of interest.

\section{Acknowledgments}

This study was supported by the National Natural Science Foundation of China under grant no. 51779130.

\section{Supplementary Materials}

Supplementary 1. Concise description for Figure 5. Figure 5: average-temperature process line of concrete prisms for four water-pipe spacing cases. Column A is time, since the start time of water flow in the concrete prism is day 1, cell (A4) is the 1.1 day, and the time step is the 0.1 day; therefore, cell (A5) is the 1.2 day, and so on. Column B is the average temperature of concrete prism for water-pipe spacing $1.0 \mathrm{~m} \times 1.0 \mathrm{~m}$ at different time. Column $\mathrm{C}$ is the average temperature of concrete prism for water-pipe spacing $1.5 \mathrm{~m} \times 1.5 \mathrm{~m}$ at different time. Column D is the average temperature of concrete prism for water-pipe spacing $1.0 \mathrm{~m} \times 1.5 \mathrm{~m}$ at different time. Column $\mathrm{E}$ is the average temperature of concrete prism for water-pipe spacing $2.0 \mathrm{~m} \times 1.5 \mathrm{~m}$ at different time.

Supplementary 2. Concise description for Figure 7. Figure 7: distribution of geometric position of average temperature of intermediate sections for four different water-pipe spacing cases. When the average temperature of concrete prism for water-pipe spacing $1.0 \mathrm{~m} \times 1.0 \mathrm{~m}$ on the 1.1 day is set as the isothermal value, the coordinates $\mathrm{x}$ and $\mathrm{y}$ of isotherms in the intermediate section are presented in Column $\mathrm{A}$ and Column B. When the average temperature of concrete prism for water-pipe spacing $1.0 \mathrm{~m} \times 1.0 \mathrm{~m}$ on the 2.1 day is set as the isothermal value, the coordinates $\mathrm{x}$ and $\mathrm{y}$ of isotherms in the intermediate section are presented in Column C and Column $\mathrm{D}$, and so on. When the average temperature of concrete prism for water-pipe spacing $1.0 \mathrm{~m} \times 1.0 \mathrm{~m}$ on the 10.1 day is set as the isothermal value, the coordinates $\mathrm{x}$ and $\mathrm{y}$ of isotherms in the intermediate section are presented in Column $\mathrm{S}$ and Column T. The coordinates $\mathrm{x}$ and $\mathrm{y}$ are horizontal direction and vertical direction in the intermediate section, respectively. When the average temperature of concrete prism for water-pipe spacing $1.5 \mathrm{~m} \times 1.5 \mathrm{~m}$ on the 1.1 day is set as the isothermal value, the coordinates $\mathrm{x}$ and $\mathrm{y}$ of isotherms in the intermediate section are presented in Column $U$ and Column V. When the average temperature of concrete prism for water-pipe spacing $1.5 \mathrm{~m} \times 1.5 \mathrm{~m}$ on the 2.1 day is set as the isothermal value, the coordinates $\mathrm{x}$ and $\mathrm{y}$ of isotherms in the intermediate section are presented in Column $\mathrm{W}$ and Column $\mathrm{X}$, and so on. When the average temperature of concrete prism for water-pipe spacing $1.5 \mathrm{~m} \times 1.5 \mathrm{~m}$ on the 10.1 day is set as the isothermal value, the coordinates $\mathrm{x}$ and $\mathrm{y}$ of isotherms in the intermediate section are presented in Column AM and Column AN. When the average temperature of concrete prism for water-pipe spacing $1.0 \mathrm{~m} \times 1.5 \mathrm{~m}$ on the 1.1 day is set as the isothermal value, the coordinates $\mathrm{x}$ and $\mathrm{y}$ of isotherms in the intermediate section are presented in Column AO and Column AP. When the average temperature of concrete prism for water-pipe spacing $1.0 \mathrm{~m} \times 1.5 \mathrm{~m}$ on the 2.1 day is set as the isothermal value, the coordinates $\mathrm{x}$ and $y$ of isotherms in the intermediate section are presented in Column AQ and Column AR, and so on. When the average temperature of concrete prism for water-pipe spacing $1.0 \mathrm{~m} \times 1.5 \mathrm{~m}$ on the 10.1 day is set as the isothermal value, the coordinates $\mathrm{x}$ and $\mathrm{y}$ of isotherms in the intermediate section are presented in Column BG and Column BH. When the average temperature of concrete prism for water-pipe spacing $2.0 \mathrm{~m} \times 1.5 \mathrm{~m}$ on the 1.1 day is set as the isothermal value, the coordinates $\mathrm{x}$ and $\mathrm{y}$ of isotherms in the intermediate section are presented in Column BI and Column BJ. When the average temperature of concrete prism for water-pipe spacing $2.0 \mathrm{~m} \times 1.5 \mathrm{~m}$ on the 2.1 day is set as the isothermal value, the coordinates $\mathrm{x}$ and $\mathrm{y}$ of isotherms in the intermediate section are presented in Column BK and Column BL, and so on. When the average temperature of concrete prism for waterpipe spacing $2.0 \mathrm{~m} \times 1.5 \mathrm{~m}$ on the 10.1 day is set as the isothermal value, the coordinates $\mathrm{x}$ and $\mathrm{y}$ of isotherms in the intermediate section are presented in Column CA and Column CB.

Supplementary 3. Concise description for Figure 10. Figure 10: optimized position of the buried thermometer for four different water-pipe spacing cases. Optimized geometric position (coordinates $\mathrm{x}$ and $\mathrm{y}$ ) of the buried thermometer in the intermediate section for water-pipe spacing $1.0 \mathrm{~m} \times 1.0 \mathrm{~m}$ is presented in Column $\mathrm{A}$ and Column $\mathrm{B}$. The coordinates $\mathrm{x}$ and $\mathrm{y}$ are horizontal direction and vertical direction in the intermediate section, respectively. Optimized geometric position (coordinates $\mathrm{x}$ and $\mathrm{y}$ ) of the buried thermometer in the intermediate section for water-pipe spacing $1.5 \mathrm{~m} \times 1.5 \mathrm{~m}$ is presented in Column C and Column D. Optimized geometric position (coordinates $\mathrm{x}$ and $\mathrm{y}$ ) of the buried thermometer in the intermediate section for water-pipe spacing $1.0 \mathrm{~m} \times 1.5 \mathrm{~m}$ is presented in Column E and Column F. Optimized geometric position (coordinates $\mathrm{x}$ and $\mathrm{y}$ ) of the buried thermometer in the intermediate section for water-pipe spacing $2.0 \mathrm{~m} \times 1.5 \mathrm{~m}$ is presented in Column G and Column H.

\section{References}

[1] B. F. Zhu, Thermal Stresses and Temperature Control of Mass Concrete, China Water \& Power Press, Beijing, China, 2012. 
[2] B. F. Zhu, "On the feasibility of building high quality arch dams without cracking and the relevant techniques," Journal of Hydraulic Engineering, vol. 37, no. 10, pp. 1155-1162, 2006.

[3] T. P. Melhado, M. Hein, and L. C. Ruth, "The construction of hoover dam: a case study from a builder's perspective," in Proceedings of the Hoover Dam: 75th Anniversary History Symposium, pp. 346-359, 2010.

[4] F. L. Quivik, "Cooling mass concrete: Owyhee, Hoover, and building large dams," Engineering History and Heritage, vol. 166, no. 4, pp. 236-247, 2013.

[5] The Bureau of Reclamation, Cooling of Concrete Dams: Final Reports, Washington, DC, USA, Bureau of Reclamation, 1949.

[6] The Bureau of Reclamation, The Bureau of Reclamation: History Essays from The Centennial Symposium, Bureau of Reclamation, Washington, DC, USA, 2008.

[7] O. C. Zienkiewicz, R. L. Taylor, and J. Z. Zhu, The Finite Element Method: Its Basis and Fundamentals, Butterworth-Heinemann, Oxford,UK, 2013.

[8] B. F. Zhu, "Finite element analysis of the effect of pipe cooling in concrete dams," Journal of Hydraulic Engineering, no. 4, pp. 27-36, 1985.

[9] B. F. Zhu, "Equivalent equation of heat conduction in mass concrete considering the effect of pipe cooling," Journal of Hydraulic Engineering, no. 3, pp. 28-34, 1991.

[10] B. F. Zhu, "Equivalent heat conduction equation of pipe cooling in mass concrete considering influence of external temperature," Journal of Hydraulic Engineering, no. 3, pp. 49-54, 2003.

[11] Y. Y. Huang, Y. H. Zhou, and J. B. Zhou, "Energy analysis of a pipe cooling thermal conduction calculation model," HydroScience and Engineering, no. 1, pp. 78-82, 2012.

[12] Y. M. Zhu, Z. Q. Xu, J. R. He et al., "A calculation method for solving temperature field of mass concrete with cooling pipes," Journal of Yangtze River Scientific Research Institute, no. 2, pp. 19-22, 2003.

[13] J. Cheng, T. C. Li, X. Liu, and L. H. Zhao, "A 3D discrete FEM iterative algorithm for solving the water pipe cooling problems of massive concrete structures," International Journal for Numerical and Analytical Methods in Geomechanics, vol. 40, no. 4, pp. 487-508, 2016.

[14] X. Liu, C. Zhang, X. Chang, W. Zhou, Y. Cheng, and Y. Duan, "Precise simulation analysis of the thermal field in mass concrete with a pipe water cooling system," Applied Thermal Engineering, vol. 78, no. 5, pp. 449-459, 2015.

[15] B. F. Zhu, Progress in Theory and Technology of Concrete Dam, China Electric Power Press, Beijing, China, 2009.

[16] B. F. Zhu and C. R. Zhang, Research on Key Safety Technology of High Arch Dam Structure, China Water \& Power Press, Beijing, China, 2010.

[17] B. F. Zhu, "Pipe cooling of concrete dam from earlier age with smaller temperature difference and longer time," Water Resources and Hydropower Engineering, vol. 40, no. 1, pp. 4450, 2009 (Chinese).

[18] G. X. Zhang, Y. Liu, S. H. Li, and B. F. Zhu, "Research and practice of Nine-Three-One temperature control mode," Journal of Hydraulic Engineering, vol. 33, no. 2, pp. 179-184, 2014.

[19] Z. Wu, J. Li, C. Gu, and H. Su, "Review on hidden trouble detection and health diagnosis of hydraulic concrete structures," Science China Technological Sciences, vol. 50, no. S1, pp. 34-50, 2007.

[20] P. Kripakaran and I. F. Smith, "Configuring and enhancing measurement systems for damage identification," Advanced Engineering Informatics, vol. 23, no. 4, pp. 424-432, 2009.
[21] J. Liu, H. Wang, Z. Zhang, R. Zhang, L. Cao, and G. Wang, "Optimum sensor placement method for cable-stayed bridges based on damage identifiability," Journal of Southwest Jiaotong University, vol. 53, no. 1, pp. 173-181, 2018.

[22] E. Z. Moore, K. D. Murphy, and J. M. Nichols, "Optimized sensor placement for damage parameter estimation: experimental results for a cracked plate," Structural Health and Monitoring, vol. 12, no. 3, pp. 197-206, 2013.

[23] K. Zhu, C. S. Gu, J. C. Qiu et al., "Determining the optimal placement of sensors on a concrete arch dam using a quantum genetic algorithm," Journal of Sensors, vol. 2016, Article ID 2567305, 10 pages, 2016.

[24] Y. Huang, H. Zheng, K. Xia, and Y. Zhou, "Study on equivalent heat conduct of concrete using pipe cooling and equivalent time," Journal of Huazhong University of Science and Technology (Natural Science Edition), vol. 40, no. 2, pp. 45-48, 2012.

[25] Y. Y. Huang and Y. H. Zhou, "Correlation of conduction calculation model for two different cooling pipes heat," Journal of Yangtze River Scientific Research Institute, vol. 26, no. 6, pp. 56-59, 2009.

[26] B. F. Zhu, Principle and Application of Finite Element Method, China Water \& Power Press, Beijing, China, 1998. 


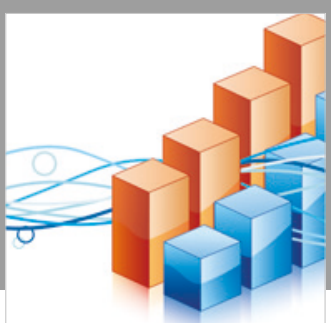

Advances in

Operations Research

\section{-n-m}
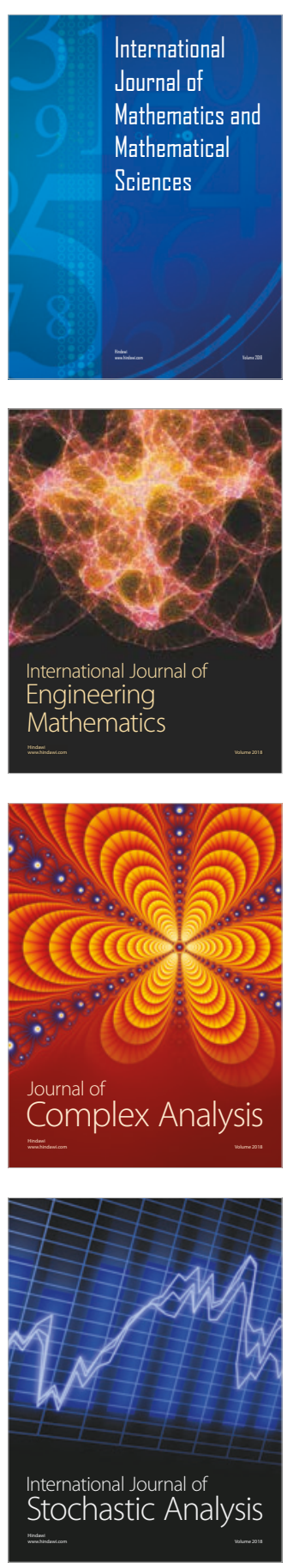
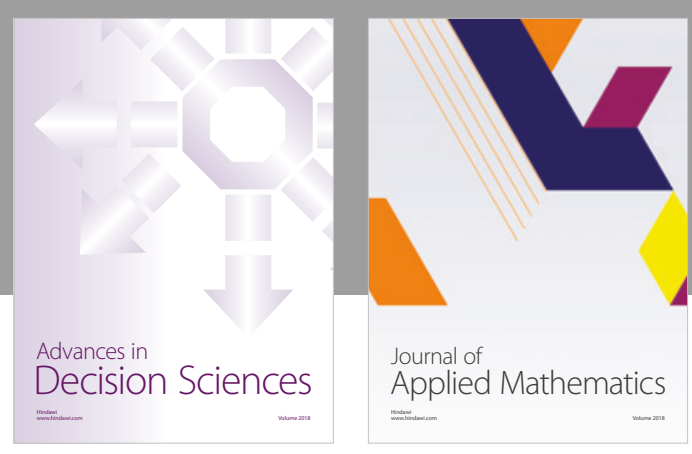

Journal of

Applied Mathematics
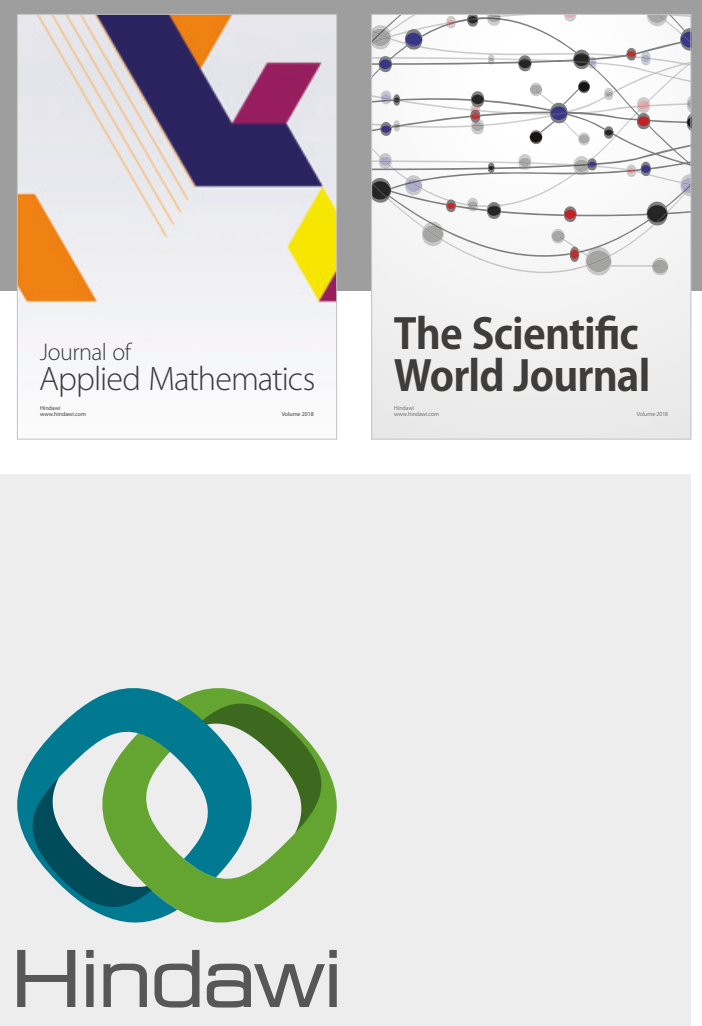

Submit your manuscripts at

www.hindawi.com

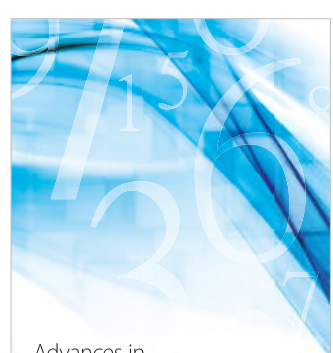

Advances in
Numerical Analysis
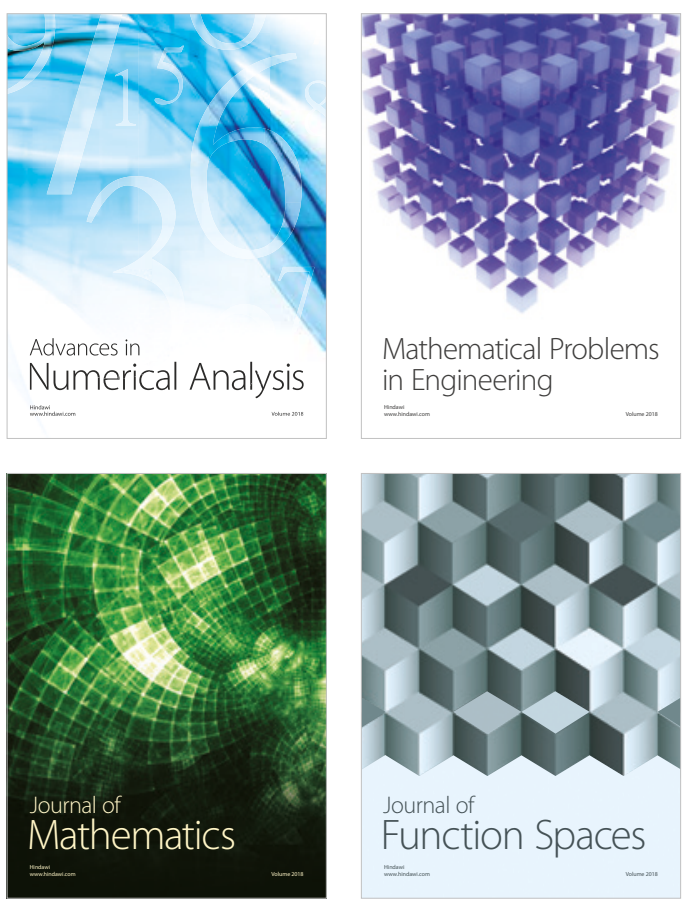

Mathematical Problems in Engineering

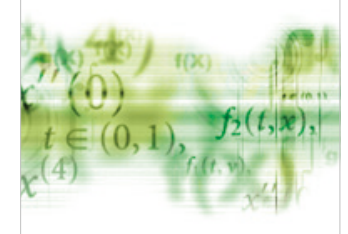

International Journal of

Differential Equations

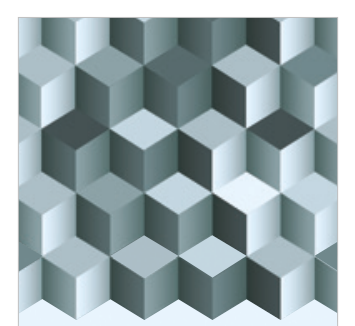

Journal of

Function Spaces
The Scientific

World Journal

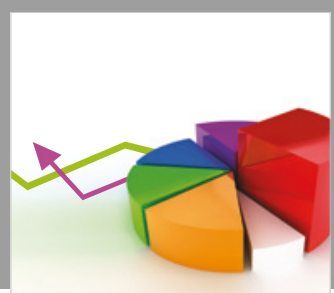

Journal of

Probability and Statistics
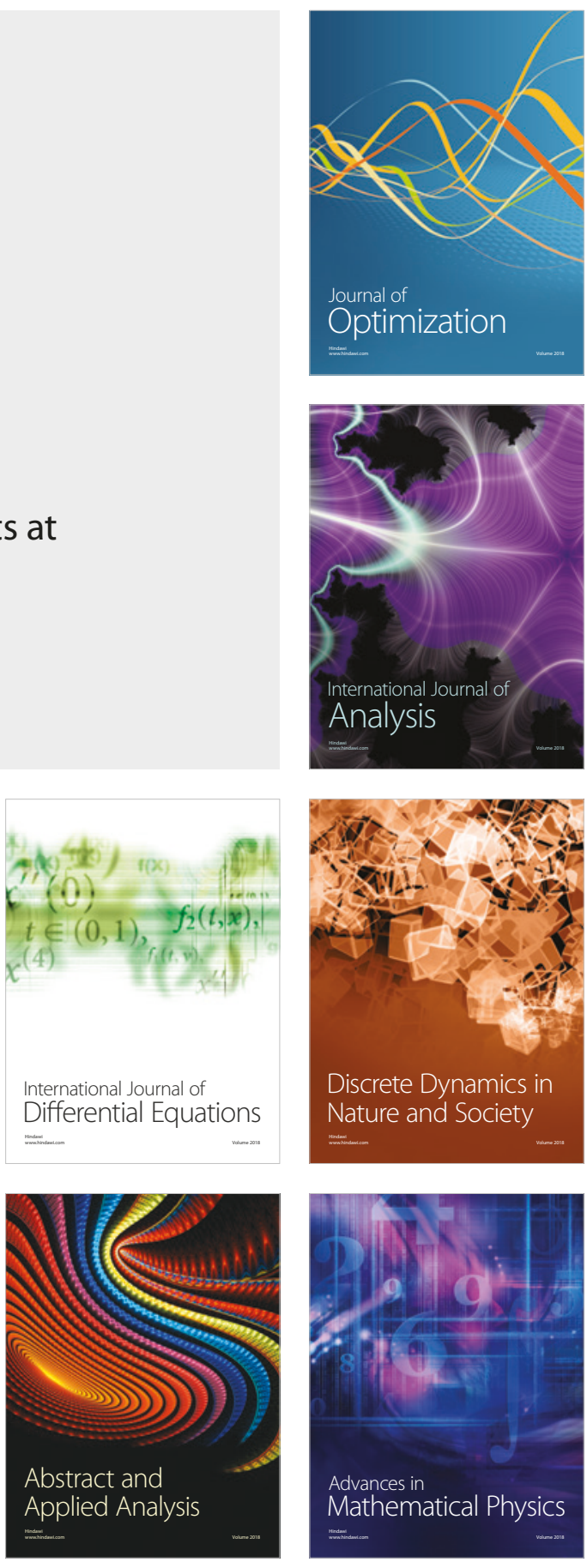